\title{
Understanding of groundwater salinity using statistical modeling in a small tropical island, East Malaysia.
}

\begin{abstract}
This paper presents an understanding of groundwater salinity by identification of effective factors using chemometric methods (cluster analysis and multiple linear regressions) in Manukan Island, Sabah. Local groundwater and environmental properties were used to explore the effective factors of groundwater salinity. Cluster analysis showed salinity and chloride illustrated the highest similarities. Electrical conductivity and total dissolved solids were also grouped in the same cluster. Seawater is the only chloride source in groundwater of Manukan Island demonstrated an indication of seawater mixing in freshwater. It is an effect of upward movement of the seawater by pumping activities. Precipitation and evapotranspiration (environmental condition) with hydraulic heads were clustered together to show that they also influence salinity concentration in groundwater. Multiple linear regressions showed descending order of the factors from chloride (the largest contribution) to evapotranspiration (the smallest contribution) and illustrated the contribution to groundwater salinity in Manukan Island. The integrated results using chemometric methods have provided a way to identify the effective factors on groundwater salinity. This similar approach and resulting equation can be applied in other small tropical islands with alike hydrogeological condition and limited information available for a better understanding of its groundwater salinity.
\end{abstract}

Keyword: Groundwater; Salinity; Factors; Chemometric methods. 